\title{
Da Impulsão à Expressividade: Uma Análise da Expressividade Artística a Partir da Filosofia Deweyana
}

Del Impulsión a la Expresividad: Un Análisis de la Expresividad Artística Basado en la Filosofía Deweyana

From Impulsion to Expressiveness: An Analysis of Artistic Expressivity Based on Deweyana Philosophy

Maria A. L. Piai

1 Professora de Filosofia e Arte da rede estadual de ensino do estado do Paraná (SEED/PR). Professora de Filosofia da Educação na Universidade Estadual do Paraná (UNESPAR). Licenciada em filosofia (UEL) e Educação Artística (UNAR) com mestrado (UEL) e doutorado (USP) em Educação.

CV: http://lattes.cnpq.br/3610869775506238.

Email: maria-piai@hotmail.com

Id-Orcid: https://orcid.org/0000-0001-5848-3357 


\section{RESUMO}

John Dewey trouxe contribuições muito significativas para nos ajudar a compreender melhor a experiência de estar e se expressar no mundo. Com base em sua filosofia da educação, este trabalho pretende apresentar e discutir a ideia de expressividade enquanto ato e objeto e, investigar por que ela se diferencia da impulsão ou ato de descarga direta. Além disso, também analisaremos qual seria o papel da experiência deweyana na expressividade artística. Com o intuído de organizar as ideias ou conceitos apresentados, o texto foi dividido em tópicos, com a pretensão apresentar e/ou responder seguintes questões: $O$ que diferencia uma impulsão ou descarga direta da emoção de um ato expressivo? Qual a relação entre a experiência e o ato expressivo? A possível diferença entre ato e o objeto expressivo? Quais as duas modalidades de respostas do ato expressivo e como elas funcionam? E, o que é necessário para que um objeto seja expressivo?

\section{PALAVRAS-CHAVE}

Ato Expressivo; Experiência; Dewey; Impulsão; Objeto Expressivo.

\section{ABSTRACT}

John Dewey has made significant contributions to help us better understand the experience of being and expressing in the world. Based on his philosophy of education, this paper aims to present and discuss the idea of expressiveness as an act and object and why it differs from the impulsion or act of direct discharge and what is the role of the Deweyan experience in artistic expressiveness. In order to organize the ideas or concepts presented, the work was divided into topics in order to answer the following questions: What differentiates a impulsion or direct discharge of emotions of an expressive act? What is the relationship between experience and the expressive act? What about the possible difference between the act and the expressive object? What are the two types of responses in the expressive act and how do they work? And, what does it take for an object to be expressive?

\section{KEYWORDS}

Act of Expressive; Experience; Dewey, Impulsion; Expressive Object.

\section{RESUMEN}

John Dewey ha hecho contribuciones significativas para ayudarnos a comprender mejor la experiencia de ser y expresarnos en el mundo. A partir de su filosofía de la educación, esta ponencia tiene como objetivo presentar y discutir la idea de la expresividad como acto y objeto y por qué se diferencia del acto de impulsión o descarga directa y, cuál es el papel de la experiencia deweyana en la expresividad artística. Con el fin de organizar las ideas o conceptos presentados, el trabajo se dividió en temas con la intención de dar respuesta a las siguientes preguntas: ¿Qué diferencia un impulso directo o descarga de emoción de un acto expresivo? ¿Cuál es la relación entre la experiencia y el acto expresivo? ¿Cuál la posible diferencia entre el acto y el objeto expresivo? ¿Cuáles son los dos tipos de respuestas en el acto expresivo y cómo funcionan? Y, ¿qué se necesita para que un objeto sea expresivo?

\section{PALABRAS CLAVE}

Acto de Expresivo; Experiencia; Dewey, Impulsión; Objeto Expresivo. 


\section{Introdução}

A interação do ser vivo com o ambiente é inerente à própria condição do viver e se constitui em situações de fruição e resistências. Essa interação pode acontecer de forma incipiente, quando ação e pensamento discordam entre si; ou de forma singular, quando se conclui o percurso dado pelo material vivenciado, integrando a criatura viva e o ambiente, sem interrupção e sem vazios.

A experiência é, para Dewey (1979), uma ação, num primeiro momento, ativopassiva; e, num segundo momento, cognição. Ativo-passiva na sua relação com o ambiente e cognitiva nas relações de continuidade e cumulatividade a que ela conduz a criatura viva. As experiências completas, segundo Dewey (2010), são aquelas atividades que convocam todo o eu a entrar em jogo.

Para Dewey, toda experiência completa começa com uma impulsão. A impulsão é definida por ele "como um movimento de todo o organismo para fora e para adiante, e dela alguns impulsos especiais são auxiliares" (DEWEY, 2010, p.143). As impulsões se originam da necessidade ou da demanda do organismo "como um todo e que só podem ser saciadas pela instituição das relações claras (relações ativas, interações) com o meio" (DEWEY, 2010, p. 144).

Há coisas que essa criatura viva precisa tomar posse para dar continuidade à vida, como por exemplo, o ar, a água, a comida, as ferramentas, a tinta do pintor, a caneta do escritor, a enxada do lavrador, o mobiliário, os amigos, as instituições sociais e as necessidades que a civilização impõe. As pulsões urgentes manifestam a necessidade de chegar numa conclusão, "através daquilo que o meio - somente ele - pode suprir". Isso denota a "dependência do eu em relação ao que o cerca para atingir suas inteirezas" (DEWEY, 2010, p.144).

A arte está associada com todos os materiais e objetivos das realizações humanas. Assim, a tarefa destacada por Dewey, para quem se dispõe a escrever sobre a filosofia das belas artes é a de

reestabelecer a continuidade entre, de um lado, as formas refinadas e intensificadas de experiência que são as obras de arte e, de outro, os eventos, atos e sofrimentos do cotidiano universalmente reconhecidos como constitutivos da experiência (DEWEY, 2010, p. 60).

Assim, a compreensão dos produtos artísticos se dá, segundo Dewey, por meio um desvio, isto é, "esquecê-los por algum tempo, virar-lhe as costas e recolher às forças e condições comuns da experiência que não acostumamos considerar estéticas" (DEWEY, 2010, p. 60).

Para Dewey, a compreensão do estético e/ou de uma teoria da arte requer a compreensão das formas brutas da experiência. É possível apreciar uma flor sem o conhecimento profundo das plantas, mas compreender o seu florescimento requer o compromisso de descobrir sua interação com o solo, sol, ar e água. A origem da arte está na experiência humana e possui essa compreensão quem nota o deleite 
das pessoas nas atividades cotidianas. Por exemplo: alguém ao remexer a lenha para melhorar o fogo, o faz pela função de melhorar o fogo, no entanto, "não deixa de ficar fascinado com o drama colorido da mudança encenada diante de seus olhos e de participar dele na imaginação" (DEWEY, 2010, 62).

Dentro dessa perspectiva deweyana de arte e da sua visão sobre a expressividade desta, esse trabalho tem como objetivo delimitar e discutir a expressividade, destacando como e por que ela se diferencia da impulsão ou ato de descarga direta, e também sobre qual seria o papel da experiência na expressividade artística, segundo o filósofo, sobretudo, nos capítulos: 'O ato expressivo' e 'O objeto expressivo', do livro 'Arte como experiência' lançado em 1934.

A fim de tornar a exposição mais didática, o texto foi dividido em subcapítulos intulados: a) Da descarga direta da emoção ao ato expressivo, no qual se busca responder: $O$ que diferencia uma impulsão ou descarga direta da emoção de um ato expressivo? b) Ato expressivo e experiência, no qual se procura apresentar o papel da experiência na formação do ato expressivo; c) A expressividade como objeto expressivo, no qual se estabelece a condição do ato e do objeto expressivo; d) As duas modalidades de respostas do ato expressivo: Colateral e Cooperativa, no qual se procura explicar quais as duas modalidades de resposta do ato expressivo e como elas funcionam e; e) O que é necessário para que um objeto/obra de arte seja expressiva? Por fim, teremos um subcapítulo de caráter conclusivo que colabora com as considerações finais, retomando as principais ideias apresentadas e entrelaçandoas com a ideia - central nessa explanação - de expressividade.

\section{Da descarga direta da emoção ao Ato Expressivo}

A criatura viva precisa se aventurar no mundo para garantir a posse daquilo que necessita e essa posse não é seu direito nato. Nessa busca, a impulsão se depara com muitas coisas e, essas coisas, podem desviá-la do seu movimento inicial. No entanto, quer o eu tenha êxito ou não, "a criatura viva ganha consciência da intenção implícita da sua impulsão" (DEWEY, 2010, p.145) e o impulso, (movimento especializado e particular, parte do mecanismo envolvido em uma adaptação mais completa ao meio) cego e instintivo, converte-se em atos planejados e cheios de sentidos. A impulsão (movimento de todo organismo para fora e para adiante com o auxílio de impulsos especiais) "nascida da necessidade, dá início a uma experiência que não sabe para onde vai" (DEWEY, 2010, p.146) e é a resistência que o meio exerce que gera a conscientização, pois essa resistência acarreta a conversão da ação direta, já que as adversidades retornam à criatura viva com significado.

Assim, a impulsão inicial ganha força e solidez, "vida e alma novas por ter de enfrentar uma nova situação." (DEWEY, 2010, p.147). A atividade ou impulsão passa a ser então um ato de expressão, pois passa a ter significado, avolumando-se e necessitando de esclarecimento e ordenamento, na medida em que incorpora as 
experiências anteriores. Em qualquer situação a impulsão e a emoção constituem o ponto de partida. $O$ crescimento da criatura acontece a partir dessa impulsão, a partir da reconstrução do movimento impulsivo e a "alternativa para uma inibição externamente imposta é a inibição através de uma reflexão e de um julgamento por parte do próprio indivíduo" (DEWEY, 2011, p. 66). A educação escolar tem papel importante nesse processo de reconstrução, pois quando os "impulsos e desejos não são organizados pela inteligência, ficam sobre o controle de circunstâncias acidentais" (DEWEY, 2011, p. 67).

Para que uma impulsão ou descarga imediata das emoções passe a ser um ato de expressão, é preciso que existam condições que desviem as manifestações diretas para "um canal em que ela seja coordenada com outras impulsões" (DEWEY, 2010, p. 201). O impulso da descarga direta de uma emoção é modificado (há um desvio). Essa modificação lhe confere um significado adicional, deixando de ser simplesmente uma impulsão para se tornar um ato de expressão.

O ato é expressivo quando há a administração das condições objetivas, quando existe a moldagem de algum material que encarne a agitação ou impulsão. Sobre isso, Dewey nos dá o exemplo do bebê: o choro inicial de um bebê é somente um impulso, mas o deixa de ser na medida em que o bebê vai percebendo as consequências que seus atos geram naqueles que o cercam (DEWEY, 2010, p. 149).

Uma atividade natural, espontânea e não intencional como o choro passa a ser executada como um recurso "para atingir uma consequência conscientemente pretendida" (DEWEY, 2010, p. 150). Assim, as "consequências vivenciadas em decorrência do agir são incorporadas como o significado de atos posteriores, porque a relação entre o fazer e o vivenciar é percebida" (DEWEY, 2010, p.150).

A expressão não descarta a turbulência. Num ato expressivo há uma descarga da emoção, mas essa emoção não é descartada, é significada e moldada em algum material, em alguma expressão corporal. E apenas "quando o material é empregado como veículo é que existem expressão e arte [...] A ligação entre um veículo e o ato expressivo é intrínseca" (DEWEY, 2010, p. 151). Assim como são necessárias as prensas e as uvas para se obter o suco, a expressão também precisa dos objetos circundantes e resistentes como a emoção e impulsão para construir a expressão da emoção (DEWEY, 2010, p. 152).

ato expressivo para Dewey não é uma inspiração, mas o seu transporte. Um poema, por exemplo, não é a inspiração, mas o transporte ou o veículo de uma emoção, impulsão ou descarga de forma consciente e ordenada por meio de um material (linguagem). Exemplificando: o poema não é inspiração para a Maria se apaixonar por alguém. Mas é um veículo que transporta a emoção de amor ou paixão da Maria de forma consciente.

No poema o material objetivo (linguagem) não é o estimulo ou ensejo evocador, mas transforma-se no conteúdo e no material da emoção. A emoção é, no ato expressivo, o ímã que atrai o material apropriado de acordo com as experiências do sujeito da emoção. A emoção atua no "sentido de acarretar a continuidade do movimento, a singularidade do efeito em meio à variedade. Ela é seletiva quanto ao 
material e diretiva quanto a sua ordenação e disposição" (DEWEY, 2010, p.160). No entanto, a emoção não constitui aquilo que é expressado.

Mas o que é arte? Para Dewey a arte é a emoção atrelada à habilidade artística. Note que habilidade artística não é arte. A explosão de emoção ou o ato de dar vazão a uma impulsão não é arte, nem expressão. Para ser um ato expressivo ou arte, a emoção tem de ser instrumentalizada, levada adiante e "perpassada pelo material aprendido e reunido" (DEWEY, 2010, p.161) buscando ordená-lo. A "arte não é natureza, mas é a natureza transformada pela entrada de novos relacionamentos, nos quais ela evoca uma resposta emocional" (DEWEY, 2010, p.176).

\section{Ato Expressivo e Experiência}

Cada pessoa "assimila dentro de si algo dos valores e significados contidos em experiências anteriores" (DEWEY, 2010, p.162). No entanto, as experiências são diferentes e essa assimilação também se dá em graus e níveis distintos, de acordo com a personalidade de cada um. O que é expressado é a união "dos aspectos da existência atual com os valores que a experiência anterior incorporou à personalidade (DEWEY, 2010, p. 163-164). Para Dewey o ato é expressivo "quando há nele um uníssono entre algo armazenado das experiências anteriores - algo generalizado, portanto - e as condições atuais" (DEWEY, 2010, p.164). As condições atuais/concretas se caracterizam pela imediatez e singularidade e, as condições das experiências anteriores se caracterizam pela generalidade.

Para que ideias cheguem à mente consciente é preciso o período de maturação no subconsciente que "precede a produção criativa em todas as áreas do esforço humano" (DEWEY, 2010, p. 166). A impulsão ou descarga direta é mecânica, ela se torna ato expressivo com a ação da inteligência que a ordena e dá novos direcionamentos.

Os artistas lidam com a qualidade das coisas da experiência direta, ou seja, os artistas tendem a pensar diretamente com as cores, sons, tons, imagens. As palavras não comportam todos os significados. A pintura, a escultura ou a música, por exemplo, têm suas próprias linguagens. A arte se constitui a partir da mudança impressa no material que é gerido de forma consciente, a "matéria primitiva e bruta da experiência precisa ser reelaborada para assegurar a expressão artística" (DEWEY, 2010, p.168).

A impulsão é administrada e submetida a um ordenamento. "O trabalho é artístico na medida em que as duas funções de transformações são executadas por uma única operação". No caso do escritor/poeta: "Enquanto o escritor compõe aquilo que quer dizer com seu veículo feito de palavras, sua ideia ganha forma perceptível para ele mesmo" (DEWEY, 2010, p.169).

Para se tornar um veículo de expressão o material objetivo sofre modificações e transformações advindas das emoções e das ideias, e provoca transformações nelas. São essas transformações e redirecionamento na (e da) emoção original que criam a 
natureza estética. A "emoção é estética quando adere a um objeto formado por um ato expressivo, no sentido no qual o ato de expressão foi definido" (DEWEY, 2010, p.170). A emoção pode ser desviada de seu fim direto, transformando-se em ato ou objeto expressivo.

A emoção passa a ser "induzida por um material expressivo e, por ser evocada por esse material e estar ligada a ele" (DEWEY, 2010, p.172), transforma-se de emoção estética para expressão estética. A expressão é o reconhecimento da emoção no espelho da arte (DEWEY, 2010, p.172). A expressão é a realidade objetiva dada à emoção de forma ordeira e, a essa emoção que se mescla ou se liga a esse material, ou realidade objetiva, é o que Dewey denomina "emoção estética".

A satisfação de ver a casa arrumada, por exemplo, é uma emoção estética. "A emoção estética, portanto, é algo distinto, mas não isolado por um abismo de outras experiências emocionais naturais" (DEWEY, 2010, p.174). Dewey ressalta a continuidade da emoção inata para chegarmos à emoção estética. $A$ "emoção estética é a emoção inata, transformada por meio do material objetivo a que ela confia seu desenvolvimento e consumação" (DEWEY, 2010, p.175).

Segundo Dewey as belas-artes são fugas ou adornos das principais atividades da vida e, nas sociedades mais bem-ordenadas as belas-artes seriam uma grande felicidade associada a todas as formas de produção. E quanto mais essa organização externa se associasse a ordenação das experiências crescentes que a envolve, mas totalizante, conclusiva e gratificante ela seria.

Quanto mais próxima da vida comum as obras de arte estão, mais unificada é a comunidade/sociedade, e mais a arte auxilia na criação da vida. A arte, para Dewey, é uma atividade que remolda a "experiência da comunidade em direção a uma ordem e união maiores" (DEWEY, 2010, p.178).

\section{A Expressividade como Objeto Expressivo}

A expressão pode significar tanto o ato como o resultado desse ato. Por esse motivo, Dewey salienta os cuidados necessários para não isolarmos um do outro, pois, muitas vezes, o objeto da expressão, visto isoladamente, leva a compreensão de que ele é representativo de outro objeto já existente, ignorando a contribuição individual da criatura viva que faz do objeto algo novo. Esse isolamento ou separação do ato expressivo e do objeto expressivo também pode levar ao engodo de que o objeto expressivo é um objeto de descarga das emoções.

Na busca incessante de combater os dualismos, Dewey salienta que estes, ou seja, as oposições

entre individual e universal, subjetivo e objetivo, liberdade e ordem, com as quais os filósofos têm relegado, não têm lugar no mundo da arte. A expressão como ato pessoal e a expressão como resultado objetivo estão organicamente ligadas (DEWEY, 2010, p.180). 
Com relação ao caráter universal atribuído ao objeto expressivo, poderíamos dizer que "tem algo em comum com outros objetos e é feito para atrair outras pessoas que não aquela que o produziu" (DEWEY, 2010, p.180). Essas qualidades em comum não são precedentes da vida e nem de um ser universal, mas no fato de que o material do ato/objeto expressivo "provém do mundo público, e por isso tem qualidades em comum com o material de outras experiências, ao passo que o produto desperta em outras pessoas a percepção dos significados do mundo comum" (DEWEY, 2010, p.180).

Desta forma, a expressividade da arte não está restritamente atrelada a uma representação ou significado que lhe seja próprio, mas se há uma característica singular da arte, esta, segundo Dewey, é "a de esclarecer e concentrar os significados que se acham contidos de maneiras dispersas e enfraquecidas no material de outras experiências" (DEWEY, 2010, p.182). A arte trabalha com a expressão de significados. As pretensões afirmativas são da ciência, a arte trabalha com a expressão das experiências que se objetivam num material moldado pela experiência, pela relação do eu com o meio. A obra de arte resulta de uma escolha do artista e, ao escolher, ele segue a lógica de seu próprio interesse.

O artista sempre se aproxima de uma cena com algum interesse e esse interesse é proveniente de suas experiências anteriores. O desenho não é um meio para garantir a expressividade de uma obra de arte (a pintura, por exemplo), mas um valor agregado a ela. O desenho ajuda a extrair do tema o que o pintor tem a dizer em sua experiência integrada.

O desenho, ou suas linhas, tem sua expressividade limitada, mas esteticamente traçado colabora para o aumento da expressividade da obra como um todo. $\bigcirc$ "ser vivo que está a adquirir experiência, participa intimamente das atividades do mundo a que pertence" (DEWEY, 1979, p.371). Nessa relação com o mundo ele adquire conhecimento e esse conhecimento não é resultado de uma "contemplação ociosa de um espectador desinteressado" (DEWEY, 1979, p.371), mas de uma experimentação ativa.

\section{As duas modalidades de respostas do Ato Expressivo: colateral e cooperativa}

Na percepção estética há duas modalidades de resposta: a colateral (motor) e a cooperativa, que trabalham no sentido de transformar uma descarga emocional imediata em um ato expressivo. Por meio dessas modalidades de resposta, "um incidente particular deixa de ser um estímulo à ação direta e se torna um valor em um objeto percebido" (DEWEY, 2010, p. 201).

A modalidade de resposta colateral pressupõe a existência de inclinações motoras previamente formadas (ex. bailarina, cirurgião, caçador). Sem tais disposições motoras, "nenhum ato complexo de habilidade poderia ser executado" (DEWEY, 2010, p. 202). Diante das várias situações do cotidiano, a coordenação motora adquirida 
pelas experiências passadas torna a percepção dessas situações mais aguçada e intensa, incorporando novos significados e dando mais profundidade.

Embora Dewey apresente essa discussão do ponto de vista de quem comete a ação, ele salienta que "considerações exatamente iguais se aplicam ao ponto de vista daquele que percebe" (DEWEY, 2010, p. 202). Assim, como se exige habilidades motoras de quem executa um instrumento musical ou pinta um quadro, elas estão presentes também em quem as percebe ao ouvir a música e ao apreciar a pintura.

A educação estética está permeada, segundo Dewey, por essa preparação motora. Ele afirma que não são necessários conhecimentos muito apurados sobre cores, tintas e pinceladas para ver a imagem numa pintura. No entanto, "é preciso que já estejam prontos canais definidos de respostas motoras, em parte devido à constituição inata, e em parte, à educação pela experiência" (DEWEY, 2010, p. 203). A constituição inata significa, aqui, as condições biológicas. Podemos estimular as emoções, mais isso pode ter pouco ou nenhuma relevância sem as condições ou "linhas motoras adequada de operações" (DEWEY, 2010, p. 203).

A modalidade de resposta cooperativa pressupõe a cooperação de algo com as linhas motoras. A resposta cooperativa é o que permite, no teatro, por exemplo, enxergar a peça de forma geral, enxergar o que é expresso nela e, não somente no desempenho motor dos atores. A expressividade de uma peça teatral, por exemplo, depende dos significados e valores extraídos das experiências prévias do seu espectador. A expressividade se dá nessa cooperação ou fusão entre os conhecimentos, significados e valores adquiridos pelas experiências prévias daquele que percebe com as qualidades que são apresentadas na peça teatral/obra de arte.

Dewey afirma que as "reações técnicas, quando não equilibradas pelo suprimento desse material secundário, são tão puramente técnicas que a expressividade do objeto fica estreitamente limitada" (DEWEY, 2010, p. 204). Sem esse equilíbrio ou mistura entre o material da experiência prévia com as qualidades da arte (peça teatral, pintura, escultura, poema), essas qualidades "se mantêm como sugestões externas, e não como parte da expressividade do objeto em si" (DEWEY, 2010, p. 204). A cooperação está nessa capacidade de compreender a integração interna das coisas feita pelo sujeito.

\section{O que é necessário para que um objeto/obra de arte seja expressivo?}

A expressividade se dá "relação entre o material sensorial direto e aquilo que Ihe é incorporado por causa de experiências anteriores" (DEWEY, 2010, p. 204). Ou seja, a capacidade de compreender a integração interna das coisas feita pelo sujeito. São "os significados e valores extraídos de experiências prévias, acumulados de tal modo que se fundam com as qualidades diretamente apresentadas pela obra de arte" (DEWEY, 2010, p. 204). Assim, a expressividade estética está imbricada com as experiências do sujeito no mundo, com a relação entre o sensorial (qualidade do 
sujeito) e o material (qualidade do mundo)

Dewey faz sua crítica às teorias estéticas e as classifica em dois grupos: a) as que pressupõem que a expressividade estética é da ordem das qualidades estéticas sensoriais diretas; e b) as que pressupõe que a expressividade estética é da ordem dos materiais associados.

As teorias que pregam a expressividade estética como sendo da ordem das qualidades estéticas sensoriais diretas encontram sua natureza expressiva na atividade organizada e isolada das vivências no mundo. Para Dewey, a expressividade das linhas por si só não traz valores estéticos pertencentes "às qualidades sensoriais, em si e por si" (DEWEY, 2010, p. 205). Os diversos tipos de linhas têm diferentes qualidades estéticas imediatas, porém, elas não podem ser explicadas sem referência ao aparelho sensorial imediato nas quais estão envolvidas.

Dewey acentua que essas teorias não abordam o problema da expressividade e que, para fins didáticos ou de dissecação, podemos separar, por exemplo, os olhos do resto do corpo, mas os olhos não funcionam em isolamento, separados do corpo, pois "as qualidades sensoriais (linhas) que nos chegam por meio do aparelho visual são simultaneamente ligadas às que nos chegam dos objetos de atividades colaterais" (DEWEY, 2010, p. 206) e de experiências anteriores, incorporando significados e dando profundidade.

A natureza "não nos apresenta linhas isoladas. Em nossas experiências, elas são linhas dos objetos; fronteiras das coisas" (DEWEY, 2010, p.206). As linhas são as formas pelas quais reconhecemos os objetos a nossa volta e, segundo Dewey, por mais que tentamos contemplá-las isoladamente, elas sempre nos remetem aos objetos pelas quais se apresentam. Elas são "expressivas das cenas naturais que já definiram para nós. Embora demarquem e definam objetos, elas também os reúnem e os ligam" (DEWEY, 2010, p. 206). Elas carregam em si as propriedades dos objetos (DEWEY, 2010, p. 207).

Mesmo que nos esforcemos para separar a experiência das linhas dos objetos, não poderíamos nos livrar, segundo Dewey, das suas propriedades habituais (linhas e movimentos), pois elas estão profundamente arraigadas. Dewey afirma que essas "propriedades são ressonâncias de uma multiplicidade de experiências, nas quais, em nosso interesse pelos objetos, nem se quer nos conscientizamos de linhas como tais" (DEWEY, 2010, p. 207). Os tipos de linhas e a relação entre esses diferentes tipos de linhas são informações que "ficam inconscientemente carregadas de todos os valores resultantes do que elas já fizeram em nossas experiências, em todos os nossos contatos com o mundo que nos cerca" (DEWEY, 2010, p. 207). Para o autor, numa pintura, essa expressividade da linha não pode ser compreendida de outra forma.

As teorias que pregam a expressividade estética como sendo da ordem dos materiais associados transformam as relações motoras em formas e

nega que as qualidades sensoriais imediatas tenham qualquer expressividade; afirma que o sensório funciona apenas como um veículo externo cujo meio outros significados nos são transmitidos" (DEWEY, 20210, p. 207). 
Negando a "ideia de que nossa percepção estética seja uma projeção, nos objetos, de uma mímica interna de suas propriedades, uma projeção que pomos em ato ao olhá-los" (DEWEY, 2010, p. 208).

Dewey faz referências ao trabalho de Vernon Lee, escritora francesa do final do século XIX e início do século XX, defensora dessa ideia que, segundo Dewey, não "passa de uma teoria animista da teoria clássica da representação" (DEWEY, 20210, p. 208). Vernon Lee, juntamente com outros teóricos do campo da estética, defende a ideia de que a arte é "um grupo de atividades que são, respectivamente, registradoras, construtivas, lógicas e comunicativas" (DEWEY, 2010, p. 208).

Caso isso estivesse correto, não haveria nada de estético na arte em si. As qualidades sensoriais diretas acabam por ser irrelevantes, já que o que define o produto estético como produto da arte é a forma, ou o desejo da forma, a que se propõem às qualidades sensoriais. As qualidades sensoriais, para essa teoria são inestéticas, "porque, ao contrário das relações que pomos ativamente em ato, elas nos são impostas e tendem a nos dominar" (DEWEY, 2010, p. 208). Essa teoria coloca o foco no fazer e reconhece as qualidades sensoriais como ativas, separando "o sensorial e as relações, a matéria e a forma, o ativo e o receptivo e as fases da experiência" (DEWEY, 2010, p. 209). Mas, para Dewey, não é necessário muito esforço para negá-la, pois ela por si só não se sustenta, já que é uma teoria que considera a cor (na pintura) e os tons (na música) como algo irrelevante esteticamente.

Para Dewey, "a expressividade do objeto da arte deve-se ao fato de ele apresentar uma interpenetração minuciosa e completa dos materiais do ficar sujeito a algo e do agir, incluindo-se nesse último a reorganização do material trazido conosco de experiências passadas" (DEWEY, 2010, p. 210). A expressividade do objeto é, ao mesmo tempo, o "relato e a celebração da fusão completa entre aquilo por que passamos e o que nossa atividade de percepção atenta introduz no que recebemos através dos sentidos" (DEWEY, 2010, p. 210).

Dewey destaca a afirmação das nossas necessidades e hábitos vitais e questiona se esses podem ser satisfeitos simplesmente por meio de relações ou se necessitam da matéria (cor e som). E afirma que "as experiências que a arte intensifica e amplia não existem exclusivamente dentro de nós, nem consistem em relações separadas da matéria" (DEWEY, 2010, p. 211). É durante os momentos de interação mais plena com o ambiente que a criatura está mais viva, mais concentrada e mais composta. São nesses momentos em que a fusão entre o material sensorial e as relações acontecem de modo mais completo. A arte reconhece o eu no ambiente. Esse reconhecimento é a sua expressão.

\section{Considerações finais}

Dewey propõe uma teoria estética que não separe a criatura viva do mundo no qual ela vive. A vida se faz na interação "através de uma série de atos e sujeições, os quais, quando esquematizados pela psicologia, são motores e sensoriais" (DEWEY, 
2010, p. 211). O que ele quer destacar é que a obra de arte é inerente à experiência humana.

O cérebro não está separado do corpo. Ele é um órgão que realiza as adaptações recíprocas dos estímulos do ambiente e também reage a esse ambiente. O ajustamento é reciproco: o ambiente afeta a criatura viva e a criatura viva afeta o ambiente numa reciprocidade continua.

Para o filósofo o "processo de viver é contínuo; tem continuidade por ser um processo permanentemente renovado de ação sobre o meio e exposição à ação dele, juntamente com a instituição de relações entre o que se faz e o que se sofre" (DEWEY, 2010, p. 211). Percebemos então, a característica cumulativa da experiência e como essa continuidade atribui expressividade ao seu conteúdo. $\bigcirc$ mundo experimentado outrora se integra ao eu do presente que está continuamente agindo e sofrendo novas experiências.

Essa continuidade é, para Dewey, um princípio segundo o qual "algo é levado de uma situação anterior para outra posterior" (DEWEY, 2011, p.45). Embora as ocorrências físicas de uma experiência se dissipem, "algo de seu significado e valor é preservado como parte integrante do eu" (DEWEY, 2010, p. 212). Na interação com o mundo, formamos hábitos e esses hábitos nos permitem habitarmos no mundo, fazendo dele nosso lar. Fazemos dele parte das nossas experiências cotidianas.

Os objetos da experiência são expressivos e nos comunicam algo, no entanto, um sentimento de mal-estar e de indiferença, causado pela diminuição da sensibilidade e do movimento, oculta sua expressividade. A indiferença causa pela familiaridade e os preconceitos nos cegam, minimizando a importância dos objetos em favor da importância do eu. Aí a arte vem e retira os véus que encobrem "a expressividade das coisas vivenciadas, instiga-nos a sair do marasmo da rotina e permite que nos esqueçamos de nós mesmos, descobrindo-nos no prazer de experimentar o mundo à nossa volta, em suas qualidades e formas variadas" (DEWEY, 2010, p. 212). A arte "intercepta os matizes da expressividade que se encontram nos objetos e os ordena em uma nova experiência de vida" (DEWEY, 2010, p. 212).

A intenção do artista não é, segundo Dewey, necessariamente a comunicação com o outro, mas essa comunicação é consequência do seu trabalho quando atua na experiência de terceiros. Quando o artista tem algo novo a dizer e quer mandar uma mensagem especial isso acaba por limitar a expressividade de sua obra de arte gerando uma reação imediata de indiferença do público.

Segundo Dewey, isso acontece por causa do público que ainda não compreende o que o artista está dizendo, o problema está na comunicabilidade e, mais especificamente, na receptividade do público por aquilo que está sendo dito pelo artista, pois os artistas são movidos "pela profunda convicção de que [...] só podem dizer aquilo que têm a dizer" (DEWEY, 2010, p. 213). Dewey nos apresenta a expressividade da arte, que está nas obras criadas pelos artistas, afirmando que "aquilo que a obra expressa é, por assim dizer, algo que eles mesmos ansiavam por expressar" (DEWEY, 2010, p. 213). As obras de arte são, para Dewey, "os únicos meios de comunicação completa e desobstruída entre os homens" (DEWEY, 2010, p. 213). 
Está claro, para Dewey, que a emoção é essencial no ato expressivo em que se produz uma obra de arte, e isso levaria facilmente ao equívoco de que a emoção é o conteúdo significativo da obra de arte. No entanto, sua expressividade não está na emoção, mas na organização ou reorganização dos materiais trazidos pelo eu de experiências anteriores. Ela é a fusão entre as condições objetivas que se apresentam no agora e tudo que foi organizado no eu pelas experiências passadas por meio dos sentidos. Assim, o que faz com que um objeto ou um ato seja expressivo é o fato de ele ser moldado com uma nova linguagem, com significados, com uma ordenação consciente e não meramente impulsiva.

\section{Referências}

DEWEY. John. Arte como experiência. Trad. Vera Ribeiro. São Paulo: Martins Fontes, 2010.

. Democracia e educação: introdução à filosofia da educação. Trad. Godofredo Rangel e Anísio Teixeira. 4a.ed. São Paulo: Companhia Editara Nacional, 1979.

Experiência e educação. Trad. Renata Gaspar. Petrópolis: Vozes, 2011. 